\title{
Prudent Use of Antenatal Corticosteroids for Fetal Well-being
}

\author{
Narendra Malhotra ${ }^{1}$, Ruchika Garg ${ }^{2}$, Gangadhar Sahoo ${ }^{3}$, Pavika Lal ${ }^{4}$, Prasanna K Sahoo ${ }^{5}$ \\ Journal of South Asian Federation of Obstetrics and Gynaecology (2019): 10.5005/jp-journals-10006-1737
}

\section{INTRODUCTION}

Preterm birth remains one of the greatest public health challenges contributing to significant neonatal morbidity and mortality as well as adding to the economic burden especially in the low- and middle-income countries. Approximately 15 million babies are born preterm each year and 1 million die while remaining live with acute and chronic diseases associated with prematurity. Nearly $2 / 3$ of global preterm burden is contributed by South Asian and African countries, and risk of death is inversely correlated with gestational age at delivery. ${ }^{1}$ The antenatal administration of corticosteroid in pregnant female in whom preterm birth is anticipated either spontaneous or iatrogenic is one of the most revolutionary interventions in fetal medicine and now has become the standard of care globally. The universal acceptance of this treatment is due to the evidence stating significantly improved neonatal outcomes with decrease in neonatal deaths due to respiratory distress syndrome, intraventricular hemorrhage, and necrotizing enterocolitis, in first 48 hours of life. ${ }^{2}$ The main indication of antenatal corticosteroid administration is preterm labor or conditions that may lead to imminent delivery like antepartum hemorrhage, preterm premature rupture of membranes, IUGR, and severe preeclampsia, while frank chorioamnionitis is an absolute contraindication.

\section{Mechanism of Action}

The principle action is increased surfactant production as well as lung maturation (alveolar structure, vascularization, as well as air space fluid clearance) which contributes to improved neonatal respiratory function postdelivery. ${ }^{3}$ Additionally, corticosteroids have been implicated for beneficial effects on other organ systems like heart, brain, hypothalamus, kidneys, and thyroid that support postnatal adaptation.

\section{Dose of Administration}

The total recommended treatment dose for dexamethasone or betamethasone is $24 \mathrm{mg}^{4}$ Betamethasone is administered as two $12 \mathrm{mg}$ im injections of a 1:1 preparation of betamethasone phosphate and betamethasone acetate, given 24 hours apart, use of a combined preparations allows for rapid exposure to free betamethasone with dephosphorylation of betamethasone phosphate, with extended dosing provided by the slower deacetylation of microparticulate betamethasone acetate. ${ }^{5}$ Dexamethasone is commonly prescribed as dexamethasone sodium phosphate, and the regimen is four doses of $6 \mathrm{mg}$ i.m. injections at 12 hourly intervals. ${ }^{6}$

\section{Timing of Administration}

A single course of corticosteroids is recommended for pregnant women between $240 / 7$ weeks and $336 / 7$ weeks of gestation who are at risk of preterm delivery within 7 days including for those
${ }^{1}$ Rainbow IVF, Agra, Uttar Pradesh, India

${ }^{2}$ Department of Obstetrics and Gynecology, Sarojini Naidu Medical College, Agra, Uttar Pradesh, India

${ }^{3}$ Institute of Medical Sciences and SUM Hospital of Siksha 'O' Anusadhan (Deemed to be University), Bhubaneswar, Odisha, India

${ }^{4}$ Department of Obstetrics and Gynecology, Ganesh Shankar Vidyarthi Memorial Medical College, Kanpur, Uttar Pradesh, India

${ }^{5}$ Indian Academy of Paediatrics, Jaipur Road, Odisha, India

Corresponding Author: Ruchika Garg, Department of Gynecology, Sarojini Naidu Medical College, Agra, Uttar Pradesh, India, Phone: +91 9720004485, e-mail: ruchikagargagra@gmail.com

How to cite this article: Malhotra N, Garg R, Sahoo G, et al. Prudent Use of Antenatal Corticosteroids for Fetal Well-being. J South Asian Feder Obst Gynae 2019;11(5):279-280.

Source of support: Nil

Conflict of interest: None

with ruptured membranes and multiple gestations. It may also be considered for pregnant women starting at $230 / 7$ weeks of gestation who are at risk of preterm delivery within 7 days, based on family's decision regarding resuscitation irrespective of membrane rupture status and regardless of fetal number. Maximum benefit occurs when delivery happens between 24 hours and 7 days of administration. A single course of betamethasone is recommended for pregnant women between 34 0/7 weeks and 36 6/7 weeks of gestation at risk of preterm birth within 7 days and who have not received a previous course of antenatal corticosteroids. ${ }^{7}$

\section{Multiple Courses of Corticosteroid Administration}

Predicting preterm delivery is always an obstetrician dilemma which unnecessarily leads to steroid exposure to fetus who deliver at term or if delivery exceeds outside the 7 days time frame, but at the same time, there is high risk of persistence of preterm delivery. The administration of multiple doses still remains a debatable matter, and there are two schools of thought. On the one hand, scholars who support the argument for administrating repeated doses state that the beneficial effects of the therapy is lost approximately 7 days after the completion of the initial treatment and thereby increases the risk of perinatal death if delivery happens to occur after 7 days. ${ }^{8}$ On the other hand, MACS study as well as Cochrane collaboration have found no significant difference in composite primary outcome (perinatal morbidity and mortality associated with prematurity) but small and significant reductions in weight, length, and head circumference at birth in infants, and all the parameters decreased further with each additional course of antenatal corticosteroids. ${ }^{9}$ It has been observed that repeated doses have deleterious effects on fetal cerebral myelination, lung growth, and functioning of

o The Author(s). 2019 Open Access This article is distributed under the terms of the Creative Commons Attribution 4.0 International License (https://creativecommons. org/licenses/by-nc/4.0/), which permits unrestricted use, distribution, and non-commercial reproduction in any medium, provided you give appropriate credit to the original author(s) and the source, provide a link to the Creative Commons license, and indicate if changes were made. The Creative Commons Public Domain Dedication waiver (http://creativecommons.org/publicdomain/zero/1.0/) applies to the data made available in this article, unless otherwise stated. 
hypothalamo-pituitary-adrenal axis; therefore, none of the bodies (ACOG and NICHD) recommend regularly scheduled repeat or serial courses currently. ${ }^{10}$

\section{Single Rescue Course}

ACOG and World Health Organization recommend a single repeat course of antenatal corticosteroids in women who are at less than 34 weeks of gestation with a risk of preterm delivery within 7 days and whose prior course of antenatal corticosteroids was administered more than 14 days previously. ${ }^{11}$

\section{Which is Better-Dexamethasone or Betamethasone?}

Free betamethasone and dexamethasone have similar maternalfetal pharmacokinetic properties and equal affinities for corticosteroid receptors. Dexamethasone use has been associated with less alteration in fetal heart rate variability, whereas betamethasone was associated with reduced risk of periventricular leukomalacia as well as pulmonary complications when compared with dexamethasone. ${ }^{12,13} \mathrm{~A}$ recent systemic review and metaanalysis of 12 studies comparing different antenatal corticosteroid use concluded that it was unclear as to which agent (betamethasone or dexamethasone) was the better choice for antenatal therapy, and more randomized controlled trials are required further to draw any conclusion. $^{14}$

\section{Late Preterm and Early Term Gestations}

Although it has been observed that the risk of respiratory illnesses declines as gestational age increases but babies who are born late preterm (34-36 weeks) and early term (37-38 weeks) particularly with cesarean delivery, it has been seen that there is an increase in neonatal intensive care admissions due to entity termed as transient tachypnea of newborn which supports the role of administration of antenatal corticosteroids in such patients. ${ }^{15}$

\section{ConCLUSION}

The use of antenatal corticosteroids administration has prevented significant perinatal morbidity and mortality associated with prematurity, thereby being one of the noble interventions in obstetrics medicine. Single rescue dose can be given in cases where imminent delivery does not occur within 14 days of administration, but multiple courses are not recommended. Either of dexamethasone or betamethasone can be given based on availability and ease of administration as neither of them have been proven to be superior over other. At the same time, it is critical to develop strategies that encourage timely and appropriate dose of corticosteroids administration to women at risk of preterm delivery within 7 days (spontaneous or iatrogenic) and at the same time avoid overuse of steroids in low-risk women.

\section{References}

1. March of dimes, the partnership for maternal, newborn \& child health, save the children, WHO. In: Howson CP, Kinney MV, Lawn JE. Born too soon: the global action report on preterm birth. Geneva: World Health Organisation; 2012.

2. Roberts D, Dalziel S. Antenatal corticosteroids for accelerating fetal lung maturation for women at risk of preterm birth (review). Cochrane Database Syst Rev 2006(3):CD004454. DOI: 10.1002/14651858. CD004454.pub2.

3. Whitsett JA, Matsuzaki Y. Transcriptional regulation of perinatal lung maturation. Pediatr Clin North Am 2006;53(5):873-887. DOI: 10.1016/ j.pcl.2006.08.009.

4. Health NIO. The effect of antenatal steroids for fetal maturation on perinatal outcomes. NIH Consensus Statement 1994. pp. 1-24.

5. Ballard PL, Ballard RA. Scientific basis and therapeutic regimens for use of antenatal glucocorticoids. Am J Obstet Gynecol 1995;173(1):254-262. DOI: 10.1016/0002-9378(95)90210-4.

6. Jobe AH, Soll RF. Choice and dose of corticosteroid for antenatal treatments. Am J Obstet Gynecol 2004;190(4):878-881. DOI: 10.1016/ j.ajog.2004.01.044.

7. ACOG Committee Opinion, August 2017, number 713.

8. McLaughlin KJ, Crowther CA, Walker N, et al. Effects of a single course of corticosteroids given more than 7 days before birth: a systematic review. Aust N ZJ Obstet Gynaecol 2003;43(2):101-106. DOI: 10.1046/j.0004-8666.2003.00052.x.

9. Crowther CA, Haslam RR, Hiller JE, et al. Neonatal respiratory distress syndrome after repeat exposure to antenatal corticosteroids: a randomised controlled trial. Lancet 2006;367(9526):1913-1919. DOI: 10.1016/S0140-6736(06)68846-6.

10. National Institutes of Health Consensus Development Panel. Antenatal corticosteroids revisited: repeat courses - national institutes of health consensus development conference statement, august 17-18, 2000. Obstet Gynecol 2001;98(1):144-150. DOI: 10.1097/00006250-200107000-00027.

11. American College of Obstetricians and Gynecologists Committee on Obstetric Practice. Society for maternal-fetal medicine. committee opinion no. 677: antenatal corticosteroids therapy for fetal maturation. Obstet Gynecol 2016;128(4):e187-e194. DOI: 10.1097/ AOG.0000000000001715.

12. Senat MV, Minoui S, Multon $\mathrm{O}$, et al. Effect of dexamethasone and betamethasone on fetal heart rate variability in preterm labour: a randomised study. Br J Obstet Gynaecol 1998;105(7):749-755. DOI: 10.1111/j.1471-0528.1998.tb10206.x.

13. Baud O, Foix-L'Helias L, Kaminski M, et al. Antenatal glucocorticoid treatment and cystic periventricular leukomalacia in very premature infants. N Engl J Med 1999;341(16):1190-1196. DOI: 10.1056/ NEJM199910143411604.

14. Brownfoot FC, Gagliardi DI, Bain E, et al. Different corticosteroids and regimens for accelerating fetal lung maturation for women at risk of preterm birth. Cochrane Database Syst Rev 2013(8):CD006764. DOI: 10.1002/14651858.CD006764.pub3.

15. Kolas T, Saugstad OD, Daltveit AK, et al. Planned cesarean versus planned vaginal delivery at term: comparison of newborn infant outcomes. Am J Obstet Gynecol 2006;195(6):1538-1543. DOI: 10.1016/j.ajog.2006.05.005. 